\title{
PLANEJAMENTO EM SAÚDE: UMA POSSIBILIDADE DE AÇÃo PARTICIPATIVA
}

\author{
Marluce Maria Araújo Assis \\ Maria José Bistafa Pereira \\ Silvana Martins Mishima
}

ASSIS, M.M.A.; PEREIRA, M.J.B.; MISHIMA, S.M. Planejamento em saúde: uma possibilidade de ação participativa. Rev.latino-am.enfermagem, Ribeirão Preto, v. 5, n. 4, p. 55-60 , outubro 1997.

Este trabalho pretende relatar uma experiência vivenciada com o processo de planejamento integrado em uma Unidade Básica de Saúde de Ribeirão Preto-SP. Elegemos como objeto de análise as interações e diálogos que se expressaram no âmbito do Sistema Local de Saúde. Assim procuramos levar em consideração as dinâmicas particulares desta realidade e os agentes sociais envolvidos (docentes, alunos, dirigentes, trabalhadores de saúde e membros da comunidade), na tentativa de compreender o agir comunicativo segundo HABERMAS (1989). Acreditamos ser este um espaço em aberto na perspectiva de ampliar o nível de participação integrada na administração dos serviços públicos de saúde.

UNITERMOS: planejamento integrado em saúde, planejamento participativo, ação comunicativa

\section{INTRODUÇÃO}

Este trabalho apresenta uma reflexão vivenciada pelas autoras, na Disciplina de Administração de Enfermagem em Unidades de Saúde Pública, ministrada no último semestre do curso de graduação, da Escola de Enfermagem de Ribeirão Preto-Universidade de São Paulo (EERP-USP)*, onde se explicitam a dinâmica das relações entre os atores sociais envolvidos com o processo de planejamento participativo em uma Unidade Básica de Saúde da periferia de Ribeirão Preto, na área de abrangência da Região Oeste.

Desse modo, ao elegermos como objeto de discussão as interações e diálogos que se expressam através do planejamento integrado no Sistema Local de Saúde (SILOS), temos clareza que este espaço vem se revelando, como complexos de relações sociais, onde os atores teriam possibilidades de transformarem-se (a si e a outrem) numa integração participativa constante.

De certa forma, tem sido possível esta participação com o movimento de democratização da saúde desencadeado nas duas últimas décadas através de estratégias políticas racionalizadoras e socializantes (Ações Integradas de Saúde (AIS), Sistema Unificado e Descentralizado de Saúde (SUDS), e Sistema Único de Saúde (SUS) que emergiram dos confrontos entre os interesses de segmentos sociais organizados da sociedade brasileira e de iniciativas do Estado, como respostas as pressões e necessidades sociais.

Trata-se portanto, de um movimento do setor saúde que vem aglutinando intelectuais, trabalhadores de saúde, dirigentes e usuários dos serviços, num esforço compartilhado de organização, interação e diálogo, refletindo na ampliação do nível de politização das demandas e a possibilidade concreta de expandir o nível de participação popular na administração da "coisa" pública.

Nesse contexto, a Constituição Federal de 1988 (BRASIL, 1988), nos traz o direito à saúde, assegurado pelo Estado e nos garante a "participação da comunidade" no SUS (art. 198, inciso III).

Os Conselhos e Comissões de Saúde, de caráter permanente e deliberativo, foram uma conquista na Lei Orgânica da Saúde - 8.080 e 8.142 de 1990 - (BRASIL, 1990; CARVALHO \& SANTOS, 1992), estão previstos para todos os municípios e unidades prestadoras de serviços de saúde, sendo compostas por representantes dos usuários, trabalhadores de saúde e equipamentos sociais da administração pública municipal.

Este avanço no âmbito jurídico-normativo tem permitido a abertura de espaços políticos, de confrontos de interesses, de diagnóstico de necessidades e de construção de alternativas.

Como conseqüência destas articulações, a

\footnotetext{
* Participaram deste projeto docentes da EERP-USP, pós-graduanda do Programa de Doutorado Interunidades e bolsista do Programa de Aperfeiçoamento em Ensino (PAE) desta escola, enfermeira da Secretaria Municipal da Saúde (SMS) e contratada temporariamente para supervisionar estágio, bolsista de aperfeiçoamento em ensino do Projeto Integrado de Pesquisa: “O trabalho de enfermagem na organização das práticas de saúde”, alunos da disciplina, trabalhadores de saúde da UBS e usuários dos serviços.
} 
proposta de Distrito Sanitário (MENDES, 1994) que é entendido como um processo social de transformação das práticas de saúde no interior do SUS, ou seja, a gestão democrática, reorientada de acordo com princípios organizativo-assistenciais, e a população, com suas diferentes representações, demandas e necessidades delimitadas por um território; e não somente, a concepção "topográfica-burocrática", onde a proposta resume-se a uma "instância burocrática", num espaço "microregionalizado", vem sendo gestada como uma estratégia para que a Lei deixe de ser, tão somente, um instrumento que obedeça a normas legais e passe a efetivar a ampliação dos espaços democráticos.

A experiência aqui relatada, foi desenvolvida dentro desta perspectiva de reflexão coletiva, baseada em alguns trabalhos realizados em outros municípios brasileiros como Salvador (KADT \& TASCA, 1993) e São Paulo (TEIXEIRA \& MELO, 1995), que tem recebido o nome de TERRITORIALIZAÇÃO DA SAÚDE. Esta estratégia é fundamentada na concepção de Distrito Sanitário já citada, e tem como finalidade a articulação colegiada e compartilhada, entre os atores inseridos no processo (dirigentes, executores e usuários dos serviços de saúde) nos vários momentos da prática gerencial, buscando ultrapassar a separação entre informação, decisão, execução e controle das ações desenvolvidas no espaço territorial local.

\section{O CAMINHO TEÓRICO METODOLÓGICO - A OPÇÃO POR UMA ESTRATÉGIA PARTICIPATIVA}

Ao tomarmos como ponto de partida, trabalhos vivenciados em outras realidades, tínhamos clareza das especificidades inerentes a estruturas sociais concretas e diante disto, tentamos fazer um movimento de aproximação, sem perder de vista a dinâmica das relações sociais experienciadas pelos atores que dirigiam, prestavam o atendimento e usavam a unidade de saúde.

A perspectiva adotada, nos obrigou a uma revisão de conceitos, levando em consideração as dinâmicas particulares dos agentes envolvidos, e talvez, sermos capazes de entender a comunicação participativa como uma linguagem que preenche a "função da integração social ou da coordenação dos planos de diferentes atores na interação social..." (HABERMAS, 1989, p.41).

Este mesmo autor nos permite compreender esta temática a partir de três implicações importantes nos procedimentos interpretativos, a saber:

$\mathbf{1}^{\mathbf{a})}$ Os "intérpretes", referem-se as posições dos atores sociais no âmbito institucional que envolvem um saber técnico específico em determinada área do conhecimento e a ocupação de cargos dirigentes administrativos em determinado espaço institucional, conferindo-lhes um status privilegiado, ainda que temporário. No caso específico podemos citar: as autoras do trabalho, dirigentes da administração pública do município (incluindo ocupantes do cargo do nível central e local), técnicos de nível superior e lideranças comunitárias locais. Os referidos atores, renunciam à superioridade da posição privilegiada de observador, enquanto agentes sociais envolvidos nas negociações, colocando-se num processo de "crítica recíproca" entre "os sujeitos mais experientes" e/ou "os leigos", ou seja, não há uma decisão a priori "de quem tem de aprender quem";

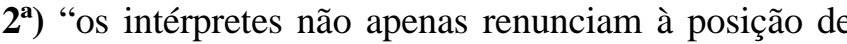
superioridade em face de seu domínio de objetos, mas confrontam-se além disso com a questão de como superar a dependência de sua interpretação relativamente no contexto", permitindo com isso, “...uma orientação mútua por pretensões de validade (verdade, correção normativa, sinceridade) que o falante ergue na expectativa de um tomada de posição por sim/não da parte do ouvinte... o falante e o ouvinte estão envolvidos, ao mesmo tempo, naquelas funções que as ações comunicativas realizam para a reprodução do mundo da vida comum...", seria uma "atitude performativa" no dizer de HABERMAS (1989, p.42-43);

$\mathbf{3}^{\mathbf{a}}$ ) "o papel de participante", intermediado pelo intérprete, não tem como pretensão "dar significado do dado de objetivações que só podem ser compreendidas a partir de processos de comunicação” (HABERMAS, 1989, p. 44)

A direção apontada nos permite remarcar que este espaço de construção democrática pode concretizar-se a partir de um trabalho coletivo, o atendimento às carências e necessidades dos trabalhadores e usuários da saúde, vislumbrando a transformação das relações sociais que se dão intra e extra locus institucional.

O projeto foi operacionalizado em etapas ou momentos, que não são estanques ou separados entre si, pois mantém uma coerência com os objetivos previstos e a dinamicidade das relações sociais estabelecidas entre "os intérpretes" (docentes, dirigentes e técnicos de saúde) e os agentes participantes (alunos, representantes da comunidade e trabalhadores de nível médio e elementar), envolvidos em significações objetivadas por um fazer "mútuo", sem deixar de reconhecer que estas relações são construídas historicamente, "como um campo de conflitos que incorpora novos significados, como a própria idéia de democracia enquanto produto da expressão do sentido das ações sociais na esfera pública" (ASSIS et al., 1995).

O primeiro momento de aproximação foi anterior ao trabalho com os alunos, onde tivemos a oportunidade de nos reunir por duas vezes com a 
Comissão Local de Saúde, um órgão colegiado participante da gestão local, coordenada formalmente, no momento da elaboração deste trabalho, pelo presidente da Associação dos Moradores de um dos bairros localizados na área de abrangência e composta por representantes de trabalhadores de saúde da unidade, representantes de instituições sociais que prestam atendimento na referida área (escolas e creches, entre outras) e membros da comunidade, para discutirmos a viabilidade de um trabalho compartilhado entre trabalhadores de saúde da unidade, docentes e alunos da Universidade e representantes da comunidade. Após várias pontuações e sugestões a nossa proposta foi aceita pelo grupo.

O segundo momento compreendeu o planejamento das necessidades sociais daquela população, que foi desdobrado em três etapas: $\mathbf{1}^{\mathbf{a}}$ ) diagnóstico/levantamento de problemas situacionais; $\mathbf{2}^{\mathbf{a}}$ ) classificação dos dados/identificação de prioridades e $\mathbf{3}^{\mathbf{a}}$ ) proposta do trabalho de campo.

O terceiro momento configurou-se em uma oficina de trabalho com participação ampliada de representantes da administração pública municipal (Secretarias da Saúde - do nível central e local, de Planejamento, de Bem Estar Social, de Educação e conselhos de Segurança dos Bairros); organizações não governamentais (Associações de Moradores, Comunidades Religiosas, Comissão de Mães); trabalhadores de saúde da unidade local e de outra unidades e Universidade (alunos e docentes da EERPUSP). Cabendo a última representação apresentar os dados coletados. Uma das docentes relatou os aspectos teóricos metodológicos e os alunos procederam uma exposição do diagnóstico situacional com as respectivas estratégias de intervenção.

Cabe colocar que esse processo de participação coletiva apresentou alguns condicionantes relacionados à disponibilidade de tempo dos membros do grupo que tiveram que conciliar atividades no exercício da prática institucional (no caso, a gerente, enfermeira da unidade e demais trabalhadores de saúde) e atividades de cunho pessoal de membros da comunidade com a necessidade curricular dos docentes e alunos, premido pelo tempo, o que por vezes conduziu a que nem todo o grupo estivesse junto o tempo todo. Entretanto, isso não representou uma fragmentação do processo.

PLANEJAMENTO INTEGRADO: UMA POSSIBILIDADE DE AÇÃO PARTICIPATIVA

Depreende-se dos depoimentos de usuários, no transcurso das discussões e visitas à comunidade local, que a transmissão de informação apresenta sua face carente, percebida pela dificuldade de entendimento do papel desempenhado pelas representações na Comissão Local de Saúde.

Por outro lado, as lideranças que representam o usuário apresentam propostas de gestão bastante vagas como: dar condições dignas de atendimento, melhorar os serviços (se prendendo muitas vezes à solicitação por serviços de atendimento médico especializado, funcionamento da unidade 24 horas para casos emergenciais, aumento do número de médicos), ou mesmo declararem não saber ao certo quais são as suas funções.

Os trabalhadores de saúde, por sua vez, ainda não conseguiram romper com a relação de dualidade entre o saber técnico (dominante) e o saber leigo (dominado).

Com esse quadro, dialético e contraditório, iniciamos o projeto participativo, organizado em várias frentes de trabalho, com diferentes olhares, mas que vislumbrava um objetivo comum. O caminhar se deu no sentido de apreendermos coletivamente, através de dinâmicas de grupo, o que significava o processo saúdedoença, as formas de organização dos serviços e a tentativa de reconstruir um novo modelo de saúde. Isto possibilitou também, que os participantes ficassem mais flexíveis e atentos à diversidade e à dinamicidade da realidade, bem como rever as concepções formuladas por cada um, procurando uma aproximação consensual com a finalidade de chegar "à compreensão conjunta de uma coisa ou a uma maneira de ver comum" (HABERMAS, 1989, p.41).

Convém lembrar que isso foi possível porque houve disponibilidade interna dos membros da equipe em partilhar a aprendizagem/construção, que pudesse subsidiar o processo de planejar em saúde, aproximando a identificação das necessidades à oferta de serviços, dirigidas para soluções dos problemas de saúde daquela comunidade.

Para um melhor clareamento do objeto de análise, sintetizamos a seguir, o segundo e terceiro momentos dessa experiência que são interdependentes e interrelacionados.

Iniciamos com a primeira etapa do segundo momento, que foi organizada tomando como base as discussões realizadas previamente. A divisão dos grupos, de alunos, usuários e trabalhadores da Unidade Básica de Saúde, orientou-se de acordo com o espaço geográfico da área de abrangência, separado por quatro bairro, definindo portanto, a mesma quantidade de subgrupos.

Procedemos a coleta de dados com um roteiro que visava identificar as barreira geográficas e sociais; condições de infraestrutura urbana (Unidades de Saúde, Escola, Creches, Igreja, Centro Comunitário), entre outros.

Ao final de cada período, reuníamos os grupos e apresentávamos o panorama geral, as dificuldades e as 
expectativas com relação às observações levantadas e o modelo teórico traçado.

Alguns conflitos tiveram que ser administrados. Um deles, foi compatibilizar o horário disponível de membros da comunidade com os dos alunos e trabalhadores da UBS. Este foi um dos motivos que levou o grupo a não estar o tempo todo junto, sendo possível em algumas situações, pelo menos um encontro semanal. Outros conflitos, difíceis de serem resolvidos, dizem respeito à compreensão distinta dos processos sociais, o partilhar poder na tomada de decisão que pode ser retratado através de situações peculiares, destacadas abaixo.

A grande ansiedade de alguns membros da comunidade em resolver questões específicas de seus bairros como a revolta de moradores com a proposta da administração municipal de uma casa-abrigo para menores abandonados; o problema das drogas com adolescentes em uma das escolas da área de abrangência, no período noturno; a falta de iluminação de um espaço institucional que servia de via de acesso entre os bairros, principalmente àquele que dispunha de maior infraestrutura para atender as comunidades adjacentes; a longa fila de espera para atendimento no serviço odontológico.

Tais conflitos, são trazidos no sentido de ilustrar a dinâmica dos confrontos que se fazem presentes numa proposta participativa, onde certamente os atores necessitam expor suas idéias e expectativas com a finalidade de um "... entendimento mútuo, ainda que seja tão somente para constatar no final um disenso" (HABERMAS, 1989, p.40).

Dada a veemência das reivindicações e na tentativa de reduzir a intensidade da pressão social, elegemos algumas prioridades em função das necessidades imediatas e que muitas vezes interviam no nível de participação da comunidade, pois exigiam ações pontuais para responder a um problema específico, e ainda minimizar as expectativas dos participantes frente ao montante das questões levantadas.

Citamos como exemplo ilustrativo, uma reunião ampliada com participantes e líderes da comunidade; representantes da Secretaria do Bem Estar Social (na pessoa do Secretário); representantes do poder legislativo; dirigente e trabalhadores da unidade de saúde; docentes e alunos da EERP-USP e membros da Comissão Local de Saúde. Este fórum teve como finalidade discutir a construção de uma casa abrigo para menores abandonados em um dos bairros da área de abrangência. Na oportunidade, a população de uma forma bastante articulada expôs suas preocupações e propostas. O Secretário, por sua vez, sensibilizou-se com a mobilização popular, revendo posições, e colocando-se como mediador dos conflitos. Houve um reencaminhamento do problema que possibilitou encontros com o promotor responsável pelo cumprimento da instalação da casaabrigo, revertendo, temporariamente, a ocupação do espaço pelos menores. Ficou acertado que a população usaria o local para atividades de educação e lazer com as crianças do bairro.

Sobre esta última questão, observamos que as relações estabelecidas na formação de solidariedade, são ainda insuficientes na sua capacidade de se comunicar, articular e traçar diretrizes entre os agentes que ocupam um espaço social comum ou semelhante, pois estes sujeitos não estão mobilizados e organizados de uma forma ampla e consistente, enquanto forças sociais para o enfrentamento contínuo e dinâmico dos problemas que aparecem nas suas vidas cotidianas. Neste sentido, parecenos que as articulações têm se dado em função de uma "necessidade" imediata, o que tem dificultado um caminhar na perspectiva de transformações sociais.

Consideramos a segunda etapa - classificação dos dados coletados/identificação de prioridades - um momento bastante significativo de aprofundamento e questionamento do grupo com discussões exaustivas e detalhadas na seleção e justificativas da problemática identificada. Neste movimento interativo e instigante, os docentes/supervisores tiveram a oportunidade de atuar como facilitadores, mediando as interações sociais entre os agentes participantes, na tentativa de compatibilizar o trabalho técnico e metodológico, que apoiasse concretamente os membros da equipe no processo cotidiano de tomada de decisão, e na definição de objetivos de representantes da comunidade que solicitavam resultados a curto prazo na solução dos problemas mais emergenciais.

O importante é que esse esforço compartilhado enriqueceu as estratégias de intervenção, na delimitação das ações a serem implementadas no espaço territorial local, configurando-se na terceira etapa do planejamento integrado.

As atividades de divulgação, referentes ao diagnóstico e identificação de prioridades (contidas no segundo momento), foram realizadas através de uma oficina de trabalho, envolvendo um fórum ampliado com várias representações da sociedade civil, pessoas da comunidade, trabalhadores de saúde, Universidade e dirigentes da administração pública municipal. Neste evento (que consideramos o terceiro momento do planejamento), estiveram em pauta três pontos essenciais: o entendimento da saúde-doença como prática individual e coletiva, que priorize o investimento na valorização da vida e suas interrelações com o ambiente cultural e social, através de ações de promoção, prevenção, cura e reabilitação, na tentativa de romper com a dicotomia prevenção X cura na edificação de uma nova prática de saúde; o segundo ponto centrou-se na 
dimensão intersetorial do projeto, constituindo-se em uma importante arma para o fortalecimento dos processos políticos de condução e decisões no âmbito do Sistema Local de Saúde, quando permite um intercâmbio com diferentes serviços como: Bem Estar Social, Educação, Segurança, entre outros, por se compreender que uma mudança de concepção no modo de fazer saúde exige ações que estão situadas fora dos limites convencionais do setor.

Com estas considerações de ordem conceitual, ideológica e política, passamos para o terceiro ponto, procedendo uma exposição dialogada e participativa (entre alunos de enfermagem e demais participantes) de aspectos técnico-operacionais, onde foram apresentados os problemas identificados e justificados, bem como as respectivas propostas de intervenção, levando os participantes a um repensar do modo de planejar e fazer saúde.

Para focalizar a dimensão específica do processo saúde-doença e a forma de gestão participativa no SILOS, realizou-se uma dramatização (peça teatral), escrita e produzida pelo dirigente e um técnico da Unidade Básica de Saúde (enfermeiro) intitulada “Ô vida!", com pessoas da comunidade e trabalhadores da UBS que relataram a vida no núcleo familiar e a utilização do serviço por parte da clientela, que só o procura para responder uma queixa imediata, demonstrando o papel complementar que os profissionais de saúde desempenham ao lidar com as intercorrências apresentadas pelo usuário. $\mathrm{Na}$ oportunidade, os "atores" fizeram esclarecimentos do que significa saúde-doença enquanto um processo social que envolve condições de vida, salários dignos, moradia, educação, transporte, segurança, entre outros. Demonstrou-se também, a necessidade do fortalecimento da Comissão Local de Saúde, como uma instância colegiada que permita um fortalecimento da gestão e avaliação do trabalho que vem sendo realizado.

A partir destas colocações, compactuamos com HABERMAS (1989) quando nos lança uma provocação de que o uso comunicativo da linguagem coloca-nos diante de um problema quando lidamos com o "consenso racionalmente motivado", pois envolve relações próprias do ser humano, consigo mesmo e com o outro e, ainda, "o compartilhar alguma coisa com alguém". E é este o nosso desafio para possibilitar um planejamento integrado e participativo.

\section{INTEGRATED PLANNING IN HEALTH: A POSSIBILITY OF A PARTICIPATIVE ACTION}

This paper intends to report an experience with the process of integrated planning in a Basic Health Unit at Ribeirão Preto-SP. We selected as our object of analysis the interactions and dialogues that were expressed in the scope of the local Health System. Therefore, we sought to consider the individual dynamics of this reality and the social agents involved (teachers, students, directors, health workers and community members), trying to understand the communicative action according to HABERMAS (1989). We believe that this is an open space in the perspective of widening the level of integrated participation in the administration of public health services.

KEY WORDS: integrated planning in health, participative planning, communicative action

\section{PLANEAMIENTO INTEGRADO DE SALUD: UNA POSSIBILITAD DE LA ACCIÓN PARTICIPATIVA}

Este trabajo intenta narrar una experiencia vivenciada con el proceso de planeamiento integrado en una Unidad Básica de Salud de Ribeirão Preto-SP. Elegimos como objeto de análisis las interacciones y los diálogos que se manifestaron distintamente en el campo de actividad del Sistema Local de Salud. Así procuramos considerar las dinámicas particulares de esta realidad y los agentes sociales comprometidos (docentes, alumnos, dirigentes, trabajadores de salud y miembros de la comunidad) en la tentativa de compreender el proceder comunicativo según HABERMAS (1989). Creemos que sea este un espacio abierto en la perspectiva de ampliar el nivel de participación integrada en la administración de los servicios públicos de salud.

TÉRMINOS CLAVES: planeamiento integrado de salud, planeamiento participativo, proceder comunicativo.

\section{REFERÊNCIAS BIBLIOGRÁFICAS}

01. ASSIS, M.M.A.; KANTORSKI, L.; TAVARES, J.L. Participação social: um espaço em construção para a conquista da cidadania. Rev.Bras.Enfermagem, 1995. (No prelo)
02. BRASIL. Constituição, 1988. Constituição da República Federativa do Brasil, 1988. Rio Grande do Sul: Ed. da Assembléia Legislativa do Estado do Rio Grande do Sul, 1988.

03. BRASIL. Lei Orgânica da Saúde - Lei no 8.080 de 19 de setembro de 1990. Saúde em Debate, n.30, p.15-20, 1990. 
04. CARVALHO, G.I.; SANTOS, L. Sistema Único de Saúde. Comentários à Lei Orgânica da Saúde (Lei 8.080 e 8.142). São Paulo: HUCITEC, 1992.

05. HABERMAS, J. Consciência moral e agir comunicativo. Rio de Janeiro: Tempo Brasileiro, 1989.

06. KADT, E. de; TASCA, R. Promovendo a equidade: um novo enfoque com base no setor saúde. São Paulo: HUCITEC, 1993.
07. MENDES E.V. (org.). Distrito Sanitário: o processo social de mudanças das práticas sanitárias do Sistema Único de Saúde. 2 ed. São Paulo: HUCITEC, 1994.

08. TEIXEIRA, C.F.; MELO, C. (Org.). Construindo distritos sanitários: a experiência da cooperação italiana no município de São Paulo. São Paulo: HUCITEC, 1995. 